\title{
Calculation of mechanical and thermal stress in the RHIC beam dump windows
}

\author{
S. Nayak, K. Yip, L. Ahrens, C. Montag
}

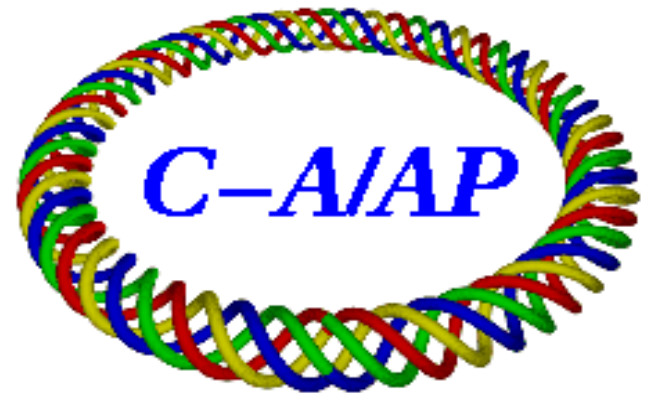

\section{Collider-Accelerator Department Brookhaven National Laboratory Upton, NY 11973}

Notice: This document has been authorized by employees of Brookhaven Science Associates, LLC under Contract No. DE-AC02-98CH10886 with the U.S. Department of Energy. The United States Government retains a nonexclusive, paid-up, irrevocable, world-wide license to publish or reproduce the published form of this document, or allow others to do so, for United States Government purposes. 


\title{
Calculation of mechanical and thermal stress in the RHIC beam dump windows
}

\author{
S. Nayak, K. Yip, L. Ahrens, C. Montag
}

March 30, 2012

\begin{abstract}
We describe the various steps in calculating the thermal stress in the RHIC beam dump windows, and list the maximum beam intensities for various species and energies to ensure safe operation of the beam dump. Furthermore, we propose a possible upgrade scenario that would increase these limits.
\end{abstract}

\section{Introduction}

The RHIC beam is aborted by horizontally deflecting it into the dump. This deflection is provided by five identical kicker modules in IR10. The dumped beam traverses a carbon block of $50 \mathrm{~cm}$ thickness before it exits the RHIC vacuum enclosure through a pair of steel windows into a second carbon block and eventually a massive steel dump, as shown in Figure 1. The carbon blocks transversely spread out the beam particles and their scattering products in order to reduce the peak energy density at the windows and the steel dump. While the first window is surrounded by vacuum on both sides, the second window is under additional mechanical stress from the outside air pressure on one side against the vacuum on the other.

Due to the kicker pulse shape the individual bunches overlap transversely at the window surface. The peak energy density at the window therefore corresponds to multiple bunches hitting the same spot at the window. This has to be taken into account when determining the thermal stress in the dump window.

In the following sections, we describe the various steps involved in computing the mechanical and thermal stress in the second dump window which is exposed to outside air pressure on one side. The analysis has been carried out for $120 \mathrm{GeV}$ gold, and $100 \mathrm{GeV}$ and $250 \mathrm{GeV}$ proton beams.

\section{Nuclear interaction and multiple scattering in the C-C carbon block}

In the first step, nuclear interaction, multiple scattering, and the accompanying energy deposition of a single bunch in the $\mathrm{C}-\mathrm{C}$ carbon block is simulated using the code MCNPX [1]. With a normalized 95 percent emittance of $\epsilon_{n}=20 \pi \mathrm{mm} \mathrm{mrad}$ and $\beta_{x, y}=20 \mathrm{~m}$ at the C-C carbon block, the initial beam size is computed as $\sigma=0.8 \mathrm{~mm}$ for $100 \mathrm{GeV}$ protons or $100 \mathrm{GeV} / \mathrm{A}$ ions, and $\sigma=0.5 \mathrm{~mm}$ for $250 \mathrm{GeV}$ protons.

Nuclear interaction and multiple scattering in the C-C carbon block widens the distribution and reduces the peak intensity significantly. The resulting distribution is best described by a double Gaussian fit,

$$
\rho(x)=A_{1} \exp \left(-\frac{x^{2}}{2 \sigma_{1}^{2}}\right)+A_{2} \exp \left(-\frac{x^{2}}{2 \sigma_{2}^{2}}\right)
$$






Figure 1: Schematic drawing of the RHIC abort kicker windows. The beam direction is from left to right. 


\begin{tabular}{|c|c|c|c|c|c|}
\hline species & energy $[\mathrm{GeV}]$ & $A_{1}\left[\mathrm{MeV} / \mathrm{cm}^{3}\right]$ & $\sigma_{1}[\mathrm{~mm}]$ & $A_{2}\left[\mathrm{MeV} / \mathrm{cm}^{3}\right]$ & $\sigma_{2}[\mathrm{~mm}]$ \\
\hline \hline protons & 100 & 218 & 0.077 & 102 & 0.170 \\
protons & 250 & 844 & 0.058 & 167 & 0.183 \\
gold & 120 & $2.04 \cdot 10^{5}$ & 0.088 & $1.06 \cdot 10^{4}$ & 0.53 \\
\hline
\end{tabular}

Table 1: Double-Gaussian fit parameters for the particle distribution on the RHIC abort window, Eq. 1.

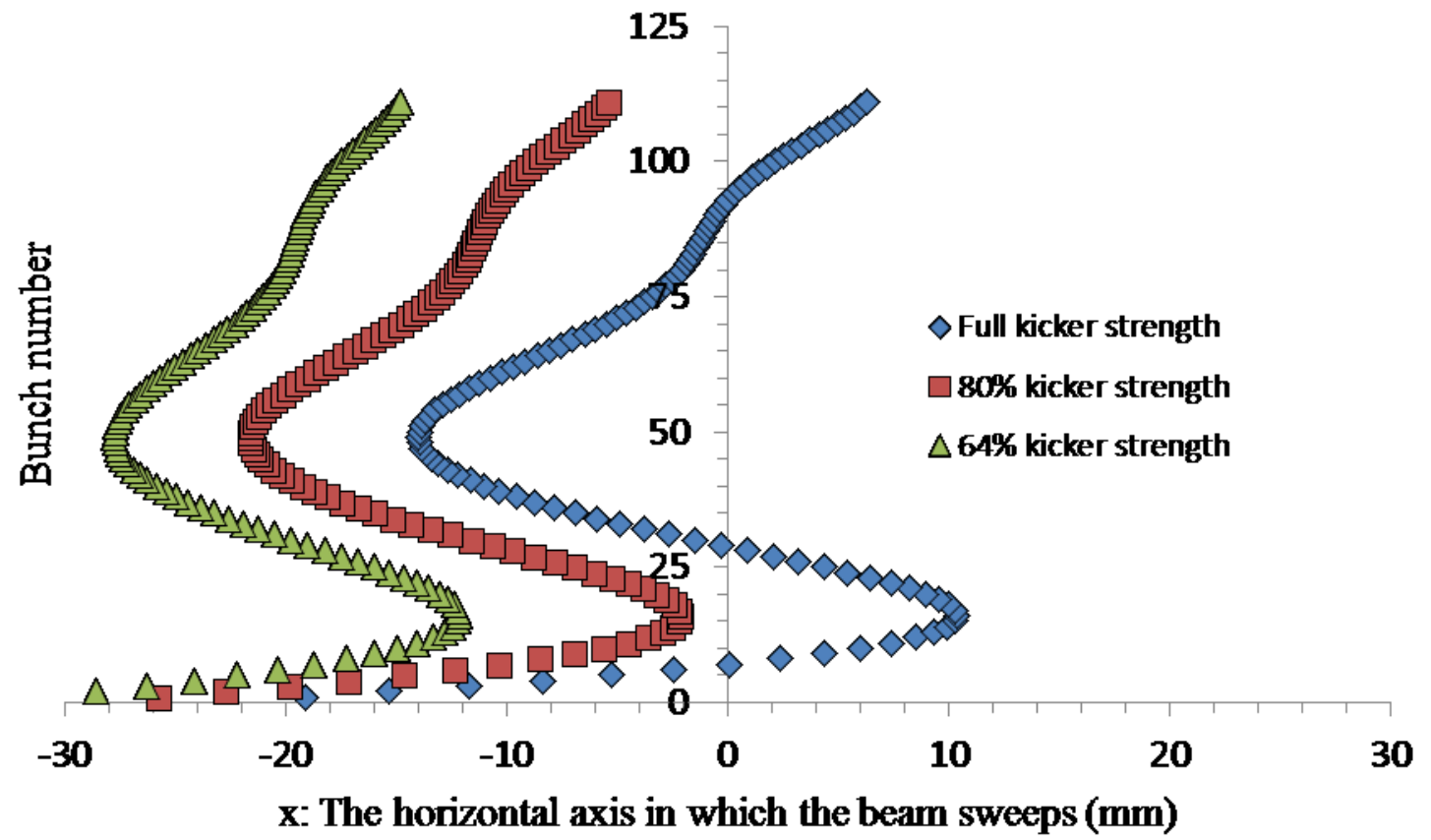

Figure 2: Kicker pulses for full kicker strength, 80 percent and 64 percent.

Table 1 lists the fit parameters for various particle species and beam energies, normalized to a single ion.

\section{The kicker pulse}

The five abort kickers deflect the beam horizontally into the beam dump. When these are triggered, the kicker pulse rises sharply before performing a non-periodic oscillation, as depicted in Figure 2. This oscillatory behavior spreads the individual bunches out in a straight line on the window surface, with several locations where several individual bunches hit the window in close vicinity. Figure 3 shows the heat input in the window due to a bunch of $1.64 \cdot 10^{9}$ gold ions at an energy of $120 \mathrm{GeV}$ as an example. 
Heat input: Full kicker strength, $120 \mathrm{GeV}$ gold at 1.64 e9 intensity

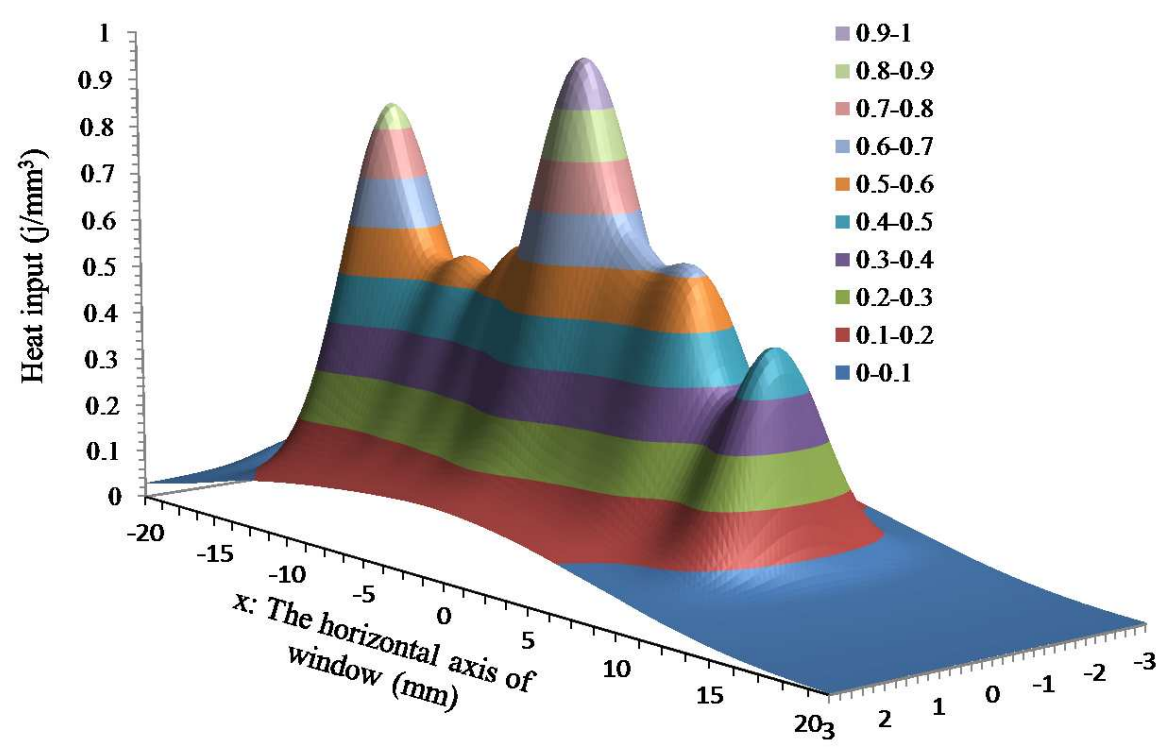

Figure 3: Heat input of 109 bunches of $1.64 \cdot 10^{9}$ gold ions at $120 \mathrm{GeV}$, deflected by full abort kicker strength. 


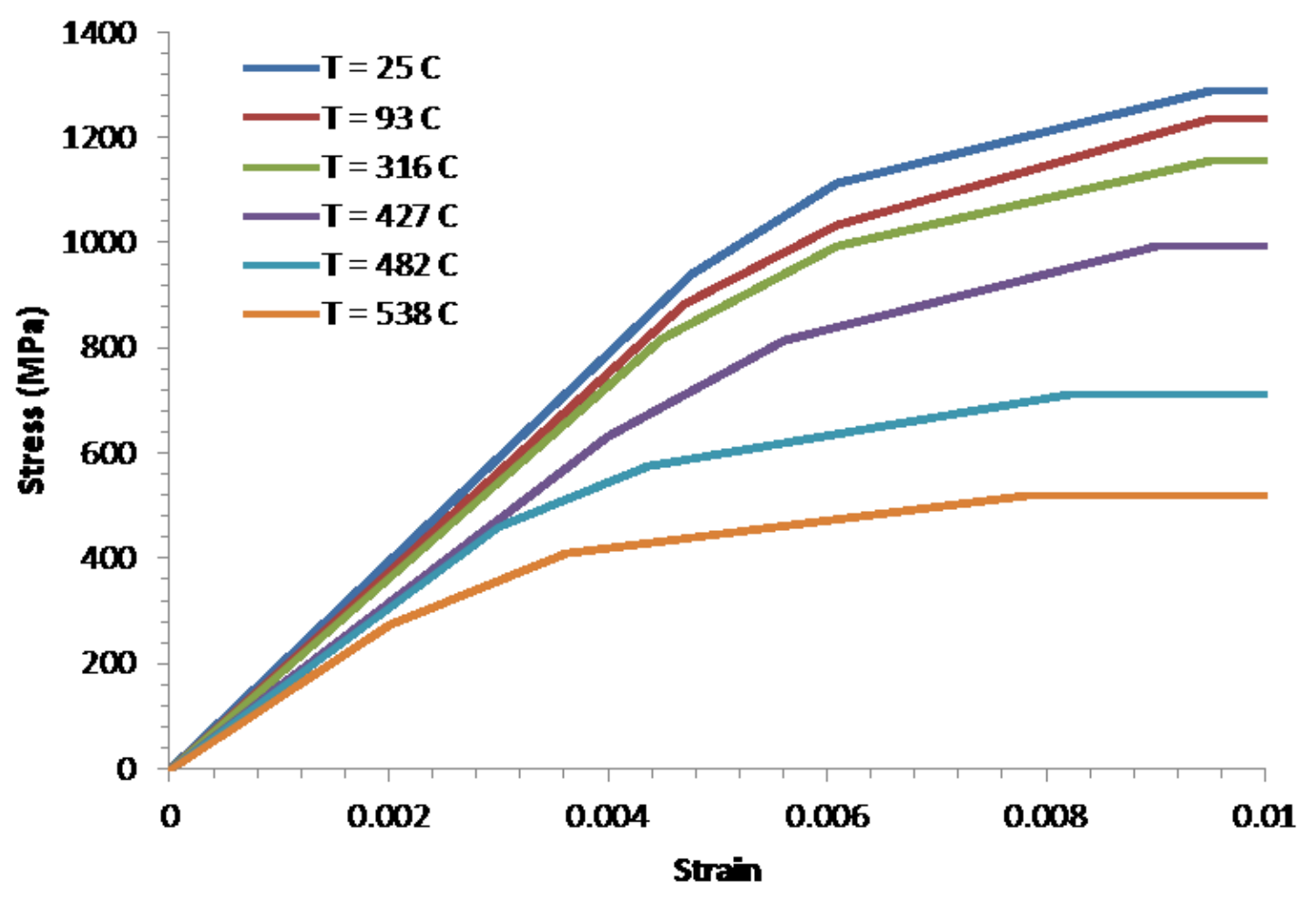

Figure 4: Stress-strain curves for 17-7 PH steel at different temperatures.

\section{Mechanical and thermal stress in the dump windows}

The RHIC beam dump windows are made of 17-7 PH high tensile steel; the properties of this material are listed in Table 2. The window dimensions are $61.5 \times 61.5 \mathrm{~mm}^{2}$ with a thickness of $1.58 \mathrm{~mm}$. When the RHIC beam hits the window, the resulting temperature increase lowers the strength of the window material, as shown in Figure 4. In the analysis, the beam intensity was varied such as to achieve a safety factor of two between VM stress and yield stress, as listed in Table 3. This results in maximum allowable intensities for three different abort kicker strengths. The full kicker strength corresponds to the design kick of $1.6 \mathrm{mrad}$, which requires a kicker voltage of $27.6 \mathrm{kV}$ for $250 \mathrm{GeV}$ protons or $100 \mathrm{GeV}$ gold ions [2]. Since this high voltage increases the risk of accidental pre-fires significantly, it is desirable to reduce it to 80 percent of that value. The 64 percent kicker strength then corresponds to the failure scenario of one of the five kicker modules, which are each set to 80 percent of the design kick, failing and therefore not providing any kick whatsoever.

\section{Conclusion}

As this analysis shows, reducing the kicker strength to 80 percent of the design value is acceptable for protons. Even if one of the five kicker modules fails in that case, a bunch intensity of $3.4 \cdot 10^{11}$ protons in each of the 109 bunches, which is beyond current intensity upgrade scenarios, still yields a safety factor of 2 for the dump window.

However, in the casem of gold ions the conclusion is quite different. Even with a full kick the maximum acceptable intensity of $1.64 \cdot 10^{9}$ gold ions per bunch in 109 bunches is not far from 


\begin{tabular}{|c|c|}
\hline Elastic modulus $[\mathrm{GPa}]$ & 197 \\
Poisson's ratio & 0.29 \\
Yield stress $[\mathrm{MPa}]$ & 940 \\
Ultimate stress $[\mathrm{MPa}]$ & 1289 \\
thermal conductivity $[\mathrm{W} /(\mathrm{m} \cdot \mathrm{K}]$ & $16.4\left(0-100^{\circ} \mathrm{C}\right), 21.8\left(500^{\circ} \mathrm{C}\right)$ \\
Thermal expansion coefficient $[\mu \mathrm{m} /(\mathrm{m} \cdot \mathrm{K})]$ & 12 \\
Emissivity & 0.8 \\
Specific heat $[\mathrm{J} /(\mathrm{kg} \cdot \mathrm{K})]$ & 460 \\
Melting point $\left[{ }^{\circ} \mathrm{C}\right]$ & $1400-1450$ \\
\hline
\end{tabular}

Table 2: Material parameters of the 17-7 PH steel used for the RHIC abort window.

\begin{tabular}{|c|c|c|c|c|}
\hline $\begin{array}{c}120 \mathrm{GeV} \text { gold } \\
\text { gold } \\
\text { intensity } \\
1.64 \cdot 10^{9} \\
1.41 \cdot 10^{9} \\
1.22 \cdot 10^{9} \\
\end{array}$ & $\begin{array}{c}\text { kicker } \\
\text { strength } \\
\text { full } \\
80 \% \\
64 \% \\
\end{array}$ & $\begin{array}{c}\text { Max. temp. } \\
{\left[{ }^{\circ} \mathrm{C}\right]} \\
\\
297.9 \\
304.75 \\
310.1 \\
\end{array}$ & $\begin{array}{c}\text { VM stress } \\
\text { pressure and } \\
\text { thermal [MPa] } \\
413.16 \\
410.2 \\
406.4 \\
\end{array}$ & $\begin{array}{c}\text { Yield stress } \\
{[\mathrm{MPa}]}\end{array}$ \\
\hline $\begin{array}{c}250 \mathrm{GeV} \text { proton } \\
\text { gold } \\
\text { intensity } \\
4.60 \cdot 10^{11} \\
3.96 \cdot 10^{11} \\
3.40 \cdot 10^{11}\end{array}$ & $\begin{array}{c}\text { kicker } \\
\text { strength } \\
\text { full } \\
80 \% \\
64 \%\end{array}$ & 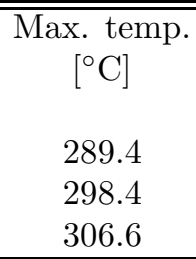 & $\begin{array}{c}\text { VM stress } \\
\text { pressure and } \\
\text { thermal [MPa] } \\
411.6 \\
410 \\
406.76\end{array}$ & $\begin{array}{c}\text { Yield stress } \\
{[\mathrm{MPa}]}\end{array}$ \\
\hline $\begin{array}{c}100 \mathrm{GeV} \text { proton } \\
\text { gold } \\
\text { intensity } \\
10.9 \cdot 10^{11} \\
9.4 \cdot 10^{11} \\
8.1 \cdot 10^{11}\end{array}$ & $\begin{array}{c}\text { kicker } \\
\text { strength } \\
\text { full } \\
80 \% \\
64 \%\end{array}$ & $\begin{array}{c}\text { Max. temp. } \\
{\left[{ }^{\circ} \mathrm{C}\right]} \\
\\
293.6 \\
299.5 \\
306.5\end{array}$ & $\begin{array}{c}\text { VM stress } \\
\text { pressure and } \\
\text { thermal [MPa] } \\
413.0 \\
409.5 \\
408.3\end{array}$ & $\begin{array}{c}\text { Yield stress } \\
\text { [MPa] } \\
\\
829.2 \\
826.8 \\
823.5\end{array}$ \\
\hline
\end{tabular}

Table 3: Resulting maximum allowable bunch intensities for protons and heavy ions, assuming 109 bunches. 
currently achieved values. Furthermore, emittance reduction efforts such as stochastic cooling result in higher energy densities at the dump window and therefore in a reduction of the maximum allowable beam intensity.

To improve the situation, spreading the bunches vertically by means of a dedicated vertical abort kicker is currently under investigation. The required kick amplitude is expected to be of the order of the beam rms beam size on the dump window, while the kicker pulse shape needs to be tuned such as to minimize the energy density resulting from overlapping bunches.

\section{References}

[1] http://mcnpx.lanl.gov/

[2] L. Ahrens, C-A/AP/23 